\title{
The corrosive effect of corruption on trust in politicians: Evidence from a natural experiment
}

Research and Politics April-June 2017: 1-8 (C) The Author(s) 2017 Reprints and permissions: sagepub.co.uk/journalsPermissions.nav DOI: $10.1 \mid 77 / 2053$ |680177|4185 journals.sagepub.com/home/rap

@SAGE

\author{
Macarena Ares' and Enrique Hernández²
}

\begin{abstract}
Empirical studies do not provide a univocal answer about the effects of corruption on political attitudes and behaviour. Focusing on the relationship between corruption and political trust, in this article we explore whether real-world corruption scandals have a negative causal effect on trust in politicians; whether the impact of scandals decays over time; and whether corruption scandals have a weaker impact among the supporters of the party involved in the scandal. We address these questions through a natural experiment generated by the coincidence of the uncovering of a corruption scandal in Spain (the Bárcenas scandal) and the fieldwork of the European Social Survey. Given that the day at which survey interviews were conducted is as-if random, the uncovering of the scandal represents a unique opportunity to assess the causal effect of corruption on individuals' trust in politicians. The results indicate that: (i) the corruption scandal had a substantial negative effect on trust in politicians; (ii) the effect of the scandal was stronger in the days following its disclosure; (iii) the effect of the scandal was independent from individuals' partisan preferences.
\end{abstract}

\section{Keywords \\ Corruption, natural experiment, trust in politicians, political support, scandals}

\section{Introduction}

In the presence of corruption we would expect citizens to develop negative orientations towards political institutions and to withdraw their support from corrupt politicians. However, empirical studies do not provide a univocal answer about the impact of corruption. Most studies identify a positive correlation between corruption, corruption scandals and different forms of political discontent (Anderson and Tverdova, 2003; Bowler and Karp, 2004). However, in the case of the electoral punishment of corrupt politicians, the identified effects of corruption range from null to moderate (Jiménez and Caínzos, 2006).

We argue that there are three reasons that could explain the diverging findings between studies of political attitudes and political behaviour. First, due to the mutual causality between measures of corruption and attitudes, previous studies might overestimate the negative effects of corruption on political attitudes. Second, the impact of corruption on attitudes might be limited in time. After a corruption scandal is uncovered individuals might develop negative attitudes towards politicians, but these attitudes might quickly recover afterwards. Third, the attitudes of individuals who sympathize with the corrupt politicians might not be affected by their wrongdoings (Anduiza et al., 2013).

To assess these three possibilities, we exploit a natural experiment generated by the coincidence of the uncovering of one of the most relevant corruption scandals to have occurred in Spain - the Bárcenas scandal - and the fieldwork of the European Social Survey (ESS). The timing of the survey is used as a source of exogenous variation in corruption, which allows us to assess the causal effect of a real-world corruption scandal on trust in politicians. Moreover, through this design we can assess whether the impact of the scandal decays, and also whether partisanship moderates the effect of the scandal.

'European University Institute, San Domenico di Fiesole, Firenze, Italia

Corresponding author:

Enrique Hernández, Universitat Autònoma de Barcelona, Av. de l'Eix Central, Edifici B2, Cerdanyola del Vallès, Barcelona, 08193, Spain.

Email: enrique.hernandez@uab.cat 


\section{Theoretical framework}

Corruption scandals make the wrongdoings of politicians known to the public. Confronted with these cases, individuals should update their attitudes towards politicians based on their judgement of the behaviour of political authorities. This is the hypothesis put forward by institutional theories, which posit that attitudes like trust in politicians are endogenous to the political system and depend on what political authorities do (Mishler and Rose, 2001). Institutions that perform well and produce desirable outputs should garner support, while the misuse of public office should lead to distrust.

In line with institutional theories, studies have identified a positive correlation between corruption, corruption scandals and political discontent. Anderson and Tverdova (2003), Mishler and Rose (2001) and Villoria et al. (2013) uncover a negative association between aggregate measures of corruption, individual-level perceptions of corruption and individuals' political support. Studies addressing the impact of specific corruption scandals have also revealed a negative effect of corruption (Bowler and Karp, 2004; Chanley et al., 2000). The negative impact of scandals is, however, not restricted to corruption. Kumlin and Esaiasson's (2012) comprehensive analysis of scandals in Europe reveals that different types of political scandals generate political discontent (see Rottinghaus, 2014 for an overview of the US literature).

Contrasting with the literature on political attitudes, studies that analyse the electoral performance of politicians involved in corruption scandals have only identified a modest, or even null, effect of corruption on the electoral fortunes of these politicians. Voters seem to forgive corrupt politicians since they are usually re-elected (Golden, 2006; Jiménez and Caínzos, 2006). Corruption has a mild effect on the electoral support of corrupt politicians across different contexts like Spain (Riera et al., 2013), Germany (Kauder and Potrafke, 2015), or Italy (Golden, 2006).

There are three possibilities that could help explain the diverging findings in studies of political attitudes and political behaviour. The first possibility is that the impact of corruption on attitudes like political distrust might have been overestimated. In previous studies corruption was often operationalized through measures of scandal recall or perceived corruption, either at the individual level through survey items (Bowler and Karp, 2004; Villoria et al., 2013), or at the aggregate level with indicators like the Corruption Perceptions Index, which are also gauged through cross-sectional individual-level surveys (Anderson and Tverdova, 2003). The findings of these studies are likely to be biased due to the mutual causality between perceptions of corruption, scandal recall and political trust. High perceptions of corruption, scandal recall and institutional mistrust generate a vicious circle of mutual reinforcement that increases the difficulty of disentangling the causal effect of corruption (Morris and Klesner, 2010).
Longitudinal and experimental designs can overcome the endogeneity problems of cross-sectional designs. However, one of the drawbacks of longitudinal studies is that the measurement of attitudes is made months or even years after the corruption scandal occurred (Chanley et al., 2000; Pharr, 2000). This is problematic since the effects of scandals are likely to weaken over time (see below). With regards to experimental designs, while they provide robust evidence of a causal effect of corruption on political attitudes (Anduiza et al., 2013; Maier, 2011), their external validity is limited. Since it is problematic to credibly manipulate real corruption scandals, most experimental research focuses on fictitious scandals. Therefore, any evidence on the effects of real corruption scandals on representative samples of the population is, thus far, limited.

We rely on a quasi-experimental design to overcome some of these limitations and analyse if real-world corruption scandals can influence trust in politicians. Drawing on institutional theories, and based on the premise that corruption scandals signal an abuse of the power entrusted by citizens to political authorities, we expect that these scandals will undermine trust in politicians. If a scandal involves high-ranking government officials, citizens should update their trust in politicians. This leads us to our first hypothesis:

$\mathbf{H}_{1}$ : Exposure to relevant and salient corruption scandals will reduce trust in politicians

Even if corruption scandals affect political attitudes, these scandals might not entail an electoral defeat of corrupt politicians if they have only a short-term effect on attitudes that has vanished by the time elections take place. The literature on media effects suggests that this might be the case, since the information conveyed in the media only exerts a short-term influence on public opinion (Gerber et al., 2011). In fact, studies indicate that the effects of political communications decay quickly (Hill et al., 2013). Moreover, if we also take into account that individuals tend to base their political opinions on top-of-the-head considerations (Zaller, 1992), we can expect that corruption scandals should inform individuals' trust in politicians to a greater extent in the weeks following their disclosure. Since the coverage of scandals should be more extensive just after they have been uncovered, scandal-related considerations should be more salient on individuals' minds during those days. Therefore, the effect of corruption scandals on political attitudes might be only short term (but cf. Doherty et al., 2014). This leads us to our second hypothesis:

$\mathbf{H}_{2}$ : The negative effect of corruption scandals on trust in politicians will be stronger in the days following their disclosure and will decay over time

The influence of corruption scandals on political attitudes and elections could also be mitigated if individuals 
react differently to scandals depending on their pre-existing attitudes. Individuals' predispositions, like their partisanship, make them react differently to political information (Zaller, 1992). Those who identify with the party involved in a scandal are likely to filter the information they receive and attribute lower importance to that scandal. Anduiza et al. (2013) have shown that partisanship moderates tolerance towards corruption. Individuals are likely to judge the corrupt actions of politicians less severely if they are committed by politicians of the party they support. Therefore, partisanship might condition how individuals react to a corruption scandal. This leads us to our final hypothesis:

$\mathbf{H}_{3}$ : The negative effects of corruption scandals on trust in politicians will be weaker among the supporters of the party involved in the scandal

\section{The Bárcenas case}

The Bárcenas case is one of the most relevant corruption scandals occurred in Spain in the last decade. It became widely known when the newspaper El País leaked internal documents from the Partido Popular (PP) on 31 January 2013. The documents leaked by El País were facsimiles written by Luis Bárcenas (the treasurer of the party) which indicated that the party had received illegal contributions that were used to pay cash bonuses to high-ranking members of the party, among other irregularities. After the publication of these documents by El Pais, news of the scandal was widely covered by national and international televisions and newspapers. While news related to Bárcenas had already appeared on 18 January in the newspaper El Mundo, the leak by El País was the first to suggest that the scandal affected not only the treasurer of the party, but also a large number of high-ranking members of the PP. In fact, on 4 February PP Prime Minister Mariano Rajoy admitted that 'nothing was true, except for a few things' (referring to the scandal documents).

To have a better picture of how the Bárcenas scandal rapidly rose in salience on 31 January, Figure 1 summarizes the relative frequencies of Google searches about the scandal. As the graph shows, the maximum peak in searches was reached the day El Pais leaked the bookkeeping documents. This is consistent with the great salience with which this issue was covered in the Spanish media. ${ }^{1}$ The figure also reveals that there was an increase in the number of searches when El Mundo presented a piece about Bárcenas, but the issue became then less salient only to peak at the end of January, coinciding with the disclosure by El Pais of the Bárcenas documents.

\section{Data and methods}

The empirical analyses draw on data from the sixth round of the ESS, which was fielded in Spain between 23 January

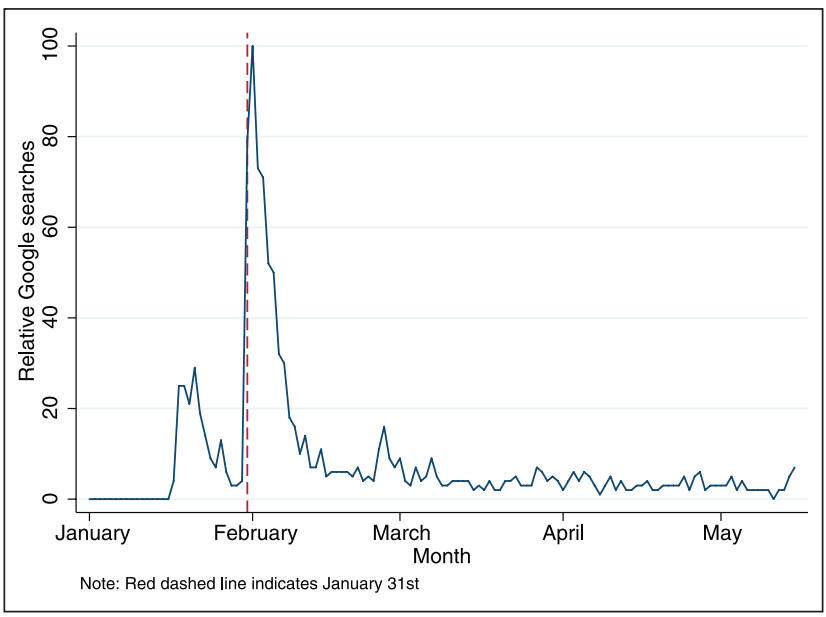

Figure I. Google trends for the search 'caso barcenas'.

and 12 May 2013. Following the research design proposed by Legewie (2013), we capitalize on the coincidence of the uncovering of the Bárcenas scandal and the ESS fieldwork. ${ }^{2}$ Our quasi-experimental identification strategy relies on the assumption that the timing at which respondents were interviewed is as-if random, so that the uncovering of the Bárcenas case provides an exogenous source of variation for levels of corruption. As such, the day at which the interview was conducted assigns respondents to the treatment and control groups. The sample is split so that those who were interviewed before the scandal are assigned to the control group and those who were interviewed in the weeks following the uncovering of the scandal are assigned to the treatment group. Therefore, the treatment variable $D_{i}$ is operationalized as follows: ${ }^{3}$

$$
D_{i}=\left\{\begin{array}{c}
D_{i}=0 \text { (control group) if subject i was interviewed } \\
\text { before } 31 \text { January }(230 \text { respondents }) \\
D_{i}=1 \text { (treatment group) if subject i was } \\
\text { interviewed between } 31 \text { January and } \\
28 \text { February (1198 respondents) }
\end{array}\right.
$$

An assumption of this identification strategy is that the timing of the survey is exogenous, and hence independent of other third variables that could affect trust in politicians (ignorability assumption). Potential threats to this assumption come from the differential reachability of the sampled respondents. If factors that determine reachability are related to political trust, there might be systematic differences in trust that are unrelated to the treatment. To assess the plausibility of this assumption, we conduct balance tests on several pre-treatment variables.

Table 1 summarizes the results of the balance tests for the following pre-treatment covariates: years of education completed, gender, age, employment status, and having 
Table I. Two-sample $t$-tests.

\begin{tabular}{|c|c|c|c|c|}
\hline \multirow[t]{2}{*}{ Variables } & \multicolumn{2}{|l|}{ Mean } & \multirow[t]{2}{*}{$p$-value } & \multirow[t]{2}{*}{ Valid $\Lambda$} \\
\hline & Treatment & Control & & \\
\hline Years of education & 12.57 & 13.07 & 0.26 & 1409 \\
\hline Gender & $1.5 \mid$ & 1.53 & 0.59 & 1428 \\
\hline Age & 46.99 & 49.39 & 0.06 & 1428 \\
\hline \multicolumn{5}{|l|}{ Employment status: } \\
\hline In paid work & 0.44 & 0.35 & 0.01 & 1422 \\
\hline In education & 0.09 & 0.11 & 0.35 & 1422 \\
\hline Unemployed & 0.16 & 0.14 & 0.47 & 1422 \\
\hline Out of the labour market & 0.29 & 0.39 & 0.01 & 1422 \\
\hline Election winner & 0.27 & 0.27 & 0.81 & 1428 \\
\hline
\end{tabular}

voted for the winning party (PP) in the last election. ${ }^{4}$ Most covariates are similarly distributed within the control and treatment groups. The only statistically significant difference between the two groups appears for employment status. There are more respondents in paid work in the treatment group and more respondents outside of the labour market in the control group. There is also a slight imbalance between the treatment and control groups with regard to age $(p$-value $=0.06)$. Overall, these tests suggest that the potential selection bias (reachability bias) exerts only a minor influence on whether individuals were interviewed before or after the scandal, and provides further support for the characterization of the event as a natural experiment.

To analyse the effect of the scandal we fit a series of OLS regressions in which trust in politicians is specified as the dependent variable. Trust in politicians is measured in an 11-point scale where 0 means no trust at all and 10 means absolute trust. Besides the treatment variable $D_{i}$ the models also include controls for the pre-treatment covariates summarized in Table 1 and region fixed effects. Region fixed effects are included to account for the fact that some regions are not present in the control group.

\section{Results}

\section{The effect of the corruption scandal $\left(H_{l}\right)$}

Figure 2 summarizes the levels of trust in politicians (a moving average of 2 days) during the months of January and February. The $x$-axis ranges from -10 to 30 , and the value 0 corresponds to 31 January. There is a substantial drop in trust in politicians on 31 January. Before the Bárcenas scandal the average level of trust in politicians in the control group is of 2.3 points. After the scandal was uncovered, the average trust in the treatment group is of 1.8 points. Thus, there is a -0.5 difference between the two groups, a reduction in trust that is quite remarkable given the already low levels of trust of Spanish citizens before the scandal.
Table 2 summarizes the results of the regression models. The treatment indicator $\mathrm{D}_{\mathrm{i}}$ of model-1 shows that respondents who were interviewed after El País uncovered the Bárcenas scandal have, on average, lower trust in politicians. The difference is of 0.48 points and statistically significant. Model-2 incorporates the pre-treatment covariates and region fixed effects. In this model the difference between those who were exposed to the Bárcenas scandal and those who were not is of -0.45 points. This difference is larger than the difference between election winners and losers, which is a common predictor of trust in politicians. Hence, in line with our first hypothesis, these models indicate that the Bárcenas scandal had a substantial negative impact on trust in politicians.

\section{Changes in the treatment effect over time $\left(\mathrm{H}_{2}\right)$}

To test $\mathrm{H}_{2}$ we estimate a series of regression models in which we progressively enlarge the treatment group by 5 days, while the control group stays always the same (those interviewed before 31 January). For the first estimation, the treatment group only comprises those interviewed on the week immediately following the scandal (31 January to 6 February), for the second estimation we also add respondents interviewed in the next 5 days (i.e. from 31 January and 11 February). We continue enlarging the treatment group by 5 days at each estimation until the final date of the fieldwork (12 May) is reached. This allows us to analyse if the treatment effects decay as we incorporate to the treatment group individuals interviewed further away from the day when the scandal was uncovered. The model estimated to test this hypothesis is specified with the same covariates of model- $2 .^{5}$

Figure 3 summarizes how the estimate for $D_{i}$ changes as individuals interviewed at a later point in time are incorporated to the treatment group. The trend line in Figure 3 displays a decay of the effect over time. When we restrict the treatment group to those interviewed just after the scandal was uncovered, the difference in trust in politicians between those who were exposed to the scandal and those who were not is of 0.50 points. As we incorporate to the treatment group individuals interviewed further away from the 


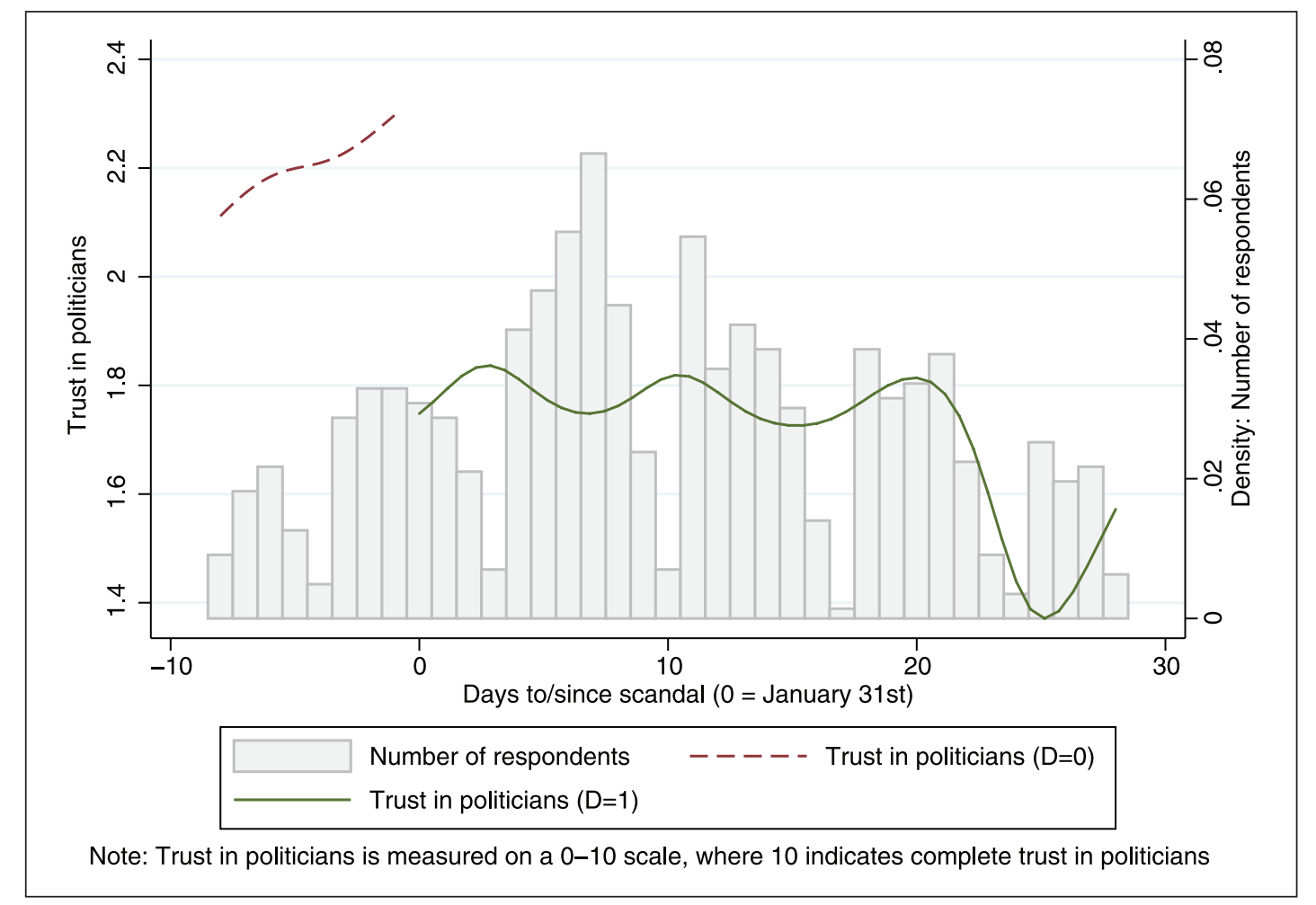

Figure 2. Change in trust in politicians at the time of the Bárcenas scandal.

scandal, the size of the coefficient $\mathrm{D}_{\mathrm{i}}$ decreases in size. In fact, when those interviewed in May are incorporated to the treatment group, the effect shrinks to -0.32 and is no longer statistically significant. These results support the idea that the scandal informed citizens' evaluations of the trustworthiness of politicians to a greater extent on the weeks that followed the publication of the Bárcenas documents. ${ }^{6}$

\section{Treatment effect heterogeneity $\left(\mathrm{H}_{3}\right)$}

To analyse the moderating role of partisan predispositions, in model- 3 of Table 2 we interact the treatment indicator $D_{i}$ and the election winner variable, which measures whether the respondent voted for the PP in the last national elections. $^{7}$ Although partisanship (i.e. being close to PP) would be a more adequate indicator of partisan predispositions, we rely on the party voted for because partisanship could be affected by the corruption scandal. The interaction coefficient indicates that there are no significant differences in the effect of being exposed to the Bárcenas scandal between those who voted for PP and those who did not. Hence, contrary to our expectations, the effects of the corruption scandal are not moderated by partisanship.

\section{Robustness checks}

One of the threats to the ignorability assumption comes from the differential reachability of respondents. To assess the robustness of our results against this potential bias, we include in our analyses information about the number of times an individual declined to reply to the survey after having been contacted, which serves as a proxy for respondents' reachability. Our estimates are not altered by the inclusion of this variable in our models (Table A2, supplementary materials). ${ }^{8}$ Moreover, some Spanish regions were only surveyed (reached) after treatment. Therefore, we reestimate all our models including only regions with respondents in both the treatment and control groups. The results indicate that our conclusions are not altered when considering only these regions (Table A2, supplementary materials).

Our identification strategy also assumes that the effect of having been interviewed before or after 31 January on trust in politicians goes only through the treatment (conditional on covariates). This assumption could be threatened by other unobserved factors that might change through time and affect trust in politicians. To evaluate this threat, we simulate 1000 placebo events that mimic our analyses of the Bárcenas scandal (i.e. control group comprises 8 days before the event and treatment group comprises 28 days after the event) but take place between 1 February and 14 April. We compare the effects of these placebo events with those of the Bárcenas scandal. It is reasonable to expect that a small proportion of the simulated events will produce results that are similar to the ones obtained with the original event, because some simulated events fall close to the date 
Table 2. OLS regression models. Dependent variable: trust in politicians.

\begin{tabular}{|c|c|c|c|}
\hline Variables & Model-I & Model-2 & Model-3 \\
\hline \multirow[t]{2}{*}{ D (Exposure to the Bárcenas scandal) } & $-0.483^{* *}$ & $-0.451 * *$ & $-0.410 *$ \\
\hline & $(0.15 I)$ & $(0.168)$ & $(0.193)$ \\
\hline \multirow[t]{2}{*}{ Election winner } & & $0.306 *$ & 0.430 \\
\hline & & $(0.130)$ & $(0.3 \mid \mathrm{I})$ \\
\hline \multirow[t]{2}{*}{ Election winner*D } & & & -0.149 \\
\hline & & & $(0.339)$ \\
\hline \multirow[t]{2}{*}{ Female } & & -0.158 & -0.157 \\
\hline & & $(0.112)$ & $(0.1 \mid 2)$ \\
\hline \multirow[t]{2}{*}{ Years of education } & & $0.027 * *$ & $0.027 * *$ \\
\hline & & $(0.010)$ & $(0.010)$ \\
\hline \multirow[t]{2}{*}{ Age } & & 0.009 & 0.009 \\
\hline & & $(0.005)$ & $(0.005)$ \\
\hline \multicolumn{4}{|l|}{ Employment status (Ref: In paid work) } \\
\hline \multirow{2}{*}{ In education } & & $0.698 * *$ & $0.699 * *$ \\
\hline & & $(0.228)$ & $(0.228)$ \\
\hline \multirow[t]{2}{*}{ Unemployed } & & $-0.360^{*}$ & $-0.359 *$ \\
\hline & & $(0.168)$ & $(0.169)$ \\
\hline \multirow[t]{2}{*}{ Out of the labour market } & & 0.286 & 0.284 \\
\hline & & $(0.175)$ & $(0.175)$ \\
\hline \multirow[t]{2}{*}{ Other } & & -0.565 & -0.562 \\
\hline & & $(0.526)$ & $(0.526)$ \\
\hline Region fixed effects & & $\checkmark$ & $\checkmark$ \\
\hline \multirow[t]{2}{*}{ Constant } & $2.224 * * *$ & $1.155^{* *}$ & $1.113^{* *}$ \\
\hline & $(0.138)$ & $(0.389)$ & $(0.40 I)$ \\
\hline Observations & $14 \mid 4$ & 1392 & 1392 \\
\hline R-squared & 0.007 & 0.051 & 0.051 \\
\hline
\end{tabular}

Standard errors in parentheses.

$* * * p<0.001$, ** $p<0.01$, $* p<0.05$.

when the Bárcenas scandal was uncovered. The results of the simulation add further plausibility to our causal estimate of the corruption scandal, since only $4.8 \%$ of the simulations produce a negative statistically significant effect similar to the one of the Bárcenas scandal (see appendix, supplementary materials for further details). Besides the simulation, we also assess the impact of the original treatment $D_{i}$ on alternative dependent variables that should not be affected by the Bárcenas scandal, for which we do not find any significant effect of the treatment (Table A5, supplementary materials).

As an additional robustness check, we replicate our analyses using the seventh round of the ESS. Since no corruption scandal was uncovered during the first days of the fieldwork of the seventh round, and interviews started on 23 January (like in the sixth round), this is an ideal way to test that our findings are not driven by aspects related to the timing of the fieldwork. We estimate the impact of a fictitious event that occurs on 31 January 2015. The results indicate that this event has no impact on trust in politicians (Table A6, supplementary materials). Furthermore, since the fieldwork of ESS-6 in Denmark coincided with the fieldwork in Spain, we follow Pollock et al. (2015) and use Denmark as a counterfactual and test the impact of the Bárcenas scandal among Danes. The Bárcenas scandal had no impact on trust in politicians in Denmark (Table A6, supplementary materials).

Finally, we also consider alternative methods to estimate the effects of the scandal. We estimate the effects through coarsened exact matching and entropy balancing (Blackwell et al., 2009; Hainmueller, 2012), as well as through a regression discontinuity design. The results obtained with these methods lead us to the same conclusions (Tables A7, A8 and A9, supplementary materials).

\section{Conclusion}

The natural experiment exploited in this paper provided a unique opportunity to estimate the causal effect of a real corruption scandal on trust in politicians with a great degree of internal and external validity. In line with institutional theories, our results indicate that the corruption scandal 


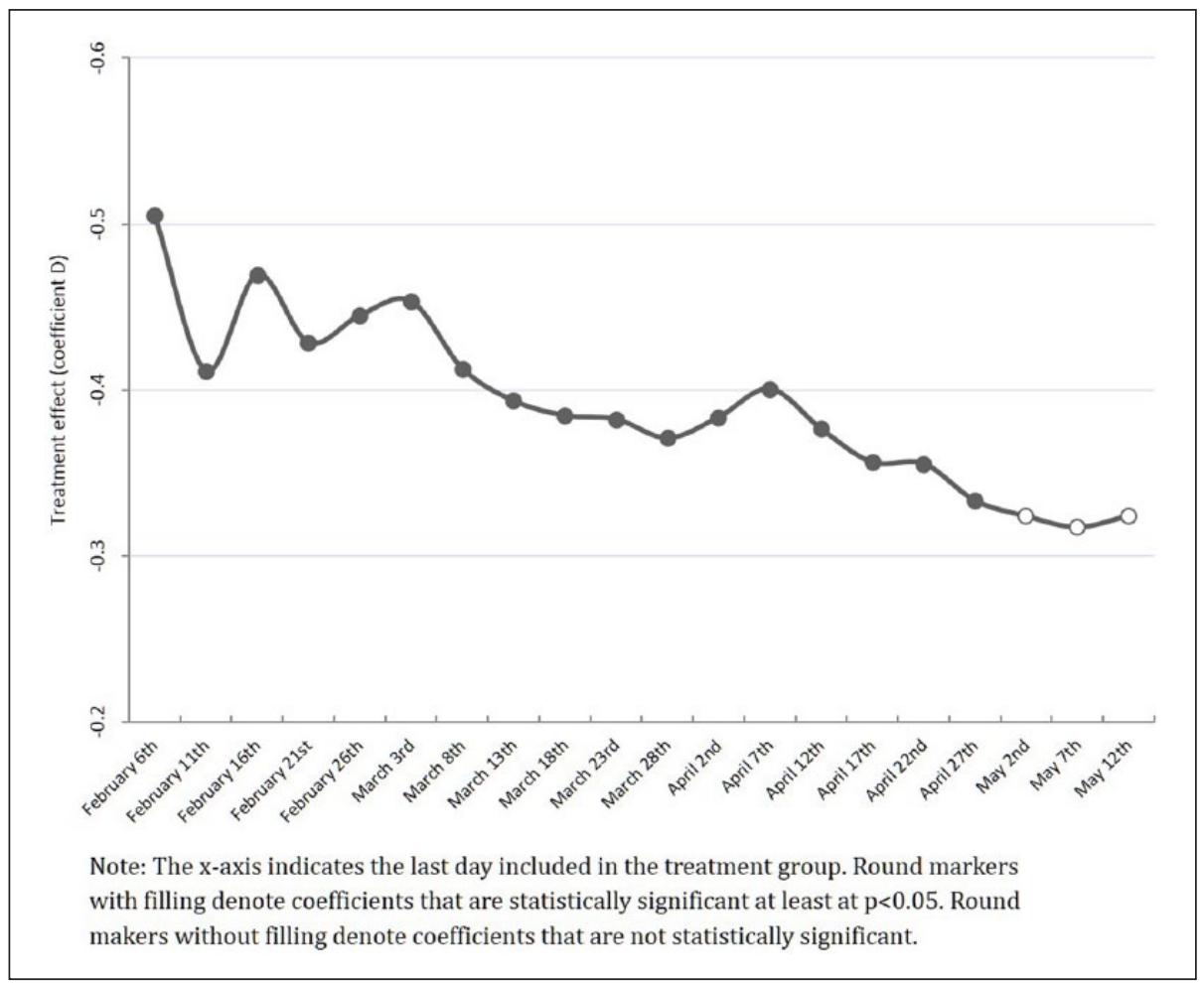

Figure 3. Change in the treatment effect over time.

Note: The $x$-axis indicates the last day included in the treatment group. Round markers with filling denote coefficients that are statistically significant at least at $p<0.05$. Round makers without filling denote coefficients that are not statistically significant.

significantly reduced individuals' trust in politicians. These results diverge from Kumlin and Esaiasson's (2012), who conclude that political scandals involving only one party do not influence attitudes towards the political system.

Through our design we also analyse the decay of the effect of the scandal. The results indicate that the impact of the corruption scandal on political trust was not longlasting, since it influenced individuals' trust in politicians more strongly in the weeks immediately following its disclosure. This finding might explain why corruption scandals have only a moderate or null influence on the electoral fortunes of corrupt politicians. This intuition seems to be supported by the performance of the party involved in the Bárcenas scandal in the 2015 and 2016 Spanish elections. Three years after the scandal was uncovered the PP lost some support in these elections but remained the most voted party.

Finally, our results indicate that the effect of the corruption scandal was not weaker among the supporters of the party involved in the scandal. The low baseline levels of trust in politicians in Spain prior to the scandal, especially among those who do not identify with the PP (average = 2.1), could explain this null finding. Low levels of trust might have predated the impact of the scandal for those not supporting PP, since for them there was already little trust in politicians to be lost before the scandal.

\section{Acknowledgements}

We would like to thank all participants for their insightful comments and suggestions. We also thank the three anonymous reviewers and the editors of Research and Politics for their valuable feedback. Previous versions of this paper were presented at the EUI Advanced Research Design Seminar, the 2015 EUI Political Behavior Colloquium, the 2016 EPSA and APSA conferences and the 2016 WAPOR regional conference on Political Trust in Contemporary Representative Democracies.

\section{Declaration of conflicting interest}

The authors declare that there is no conflict of interest.

\section{Funding}

This research received no specific grant from any funding agency in the public, commercial, or not-for-profit sectors.

\section{Supplementary material}

The supplementary files are available at http://journals.sagepub. com/doi/suppl/10.1177/2053168017714185.

\section{Notes}

1. Mellon (2013) indicates that Google trends are an appropriate measure of issue salience. To assess the extent to which Google trends also reflect the attention devoted to a topic in the media we correlate the Google trends measure with 
the number of articles mentioning Bárcenas in El Pais (extracted from Lexis/Nexis). The analyses reveal that, in the period from 1 January to 15 May the correlation between the two equals $0.73(p<0.001)$. Moreover, the peak of news about Bárcenas occurred precisely between 31 January and 5 February, when El País published 174 articles about Bárcenas. Hence, for Spain, Google trends appear to be an appropriate measure of the salience and attention devoted to a certain issue.

2. Solaz et al. (2017) follow this strategy to study the impact of the Bárcenas scandal on satisfaction with government.

3. We do not include respondents interviewed after 28 February in the treatment group because we expect the treatment to affect trust in politicians among those who were interviewed closer to the date of the treatment. To test $\mathrm{H}_{2}$ and validate this intuition we expand the original treatment group and include all respondents interviewed after 30 January (see below).

4. Details about the coding of all variables can be found in appendix A, supplementary materials.

5. We have analysed the balance on pre-treatment covariates computing means comparisons between the original control group and this enlarged treatment group. We only find statistically significant differences between the two groups for employment status.

6. We conduct additional analyses in which we divide the sample into three separate groups: those interviewed before 31 January, those interviewed between 31 January and 28 February, and those interviewed between March and May. The analyses confirm that the treatment effect decays for those interviewed after 28 February (see appendix B, supplementary materials).

7. Among those who did not vote for PP we include those who did not vote and those not eligible to vote.

8. The tables summarizing the results of the robustness checks can be found in appendix $\mathrm{C}$, supplementary materials.

\section{Carnegie Corporation of New York Grant}

This publication was made possible (in part) by a grant from Carnegie Corporation of New York. The statements made and views expressed are solely the responsibility of the author.

\section{References}

Anderson CJ and Tverdova YV (2003) Corruption, political allegiances, and attitudes toward government in contemporary democracies. American Journal of Political Science 47: 91-109.

Anduiza E, Gallego A and Muñoz J (2013) Turning a blind eye experimental evidence of partisan bias in attitudes toward corruption. Comparative Political Studies 46: 1664-1692.

Blackwell M, Iacus S, King G, et al. (2009) cem: Coarsened exact matching in Stata. The Stata Journal 9: 524-546.

Bowler S and Karp JA (2004) Politicians, scandals, and trust in government. Political Behavior 26: 271-287.

Chanley VA, Rudolph TJ and Rahn WM (2000) The origins and consequences of public trust in government: A time series analysis. Public Opinion Quarterly 64: 239-256.
Doherty D, Dowling CM and Miller MG (2014) Does time heal all wounds? Sex scandals, tax evasion, and the passage of time. PS: Political Science \& Politics 47: 357-366.

Gerber AS, Gimpel JG, Green DP, et al. (2011) How large and long-lasting are the persuasive effects of televised campaign ads? Results from a randomized field experiment. American Political Science Review 105: 135-150.

Golden MA (2006) Some puzzles of political corruption in modern advanced democracies. Unpublished manuscript.

Hainmueller J (2012) Entropy balancing for causal effects: A multivariate reweighting method to produce balanced samples in observational studies. Political Analysis 20: 25-46.

Hill SJ, Lo J, Vavreck L, et al. (2013) How quickly we forget: The duration of persuasion effects from mass communication. Political Communication 30: 521-547.

Jiménez F and Caínzos M (2006) How far and why do corruption scandals cost votes? In: Garrard J and Newell JL (eds) Scandals in Past and Contemporary Politics. Manchester: Manchester University Press, pp. 194-213.

Kauder B and Potrafke N (2015) Just hire your spouse! Evidence from a political scandal in Bavaria. European Journal of Political Economy 38: 42-54.

Kumlin S and Esaiasson P (2012) Scandal fatigue? Scandal elections and satisfaction with democracy in Western Europe, 1977-2007. British Journal of Political Science 42: 263-282.

Legewie J (2013) Terrorist events and attitudes toward immigrants: A natural experiment. American Journal of Sociology 118: 1199-1245.

Maier J (2011) The impact of political scandals on political support: An experimental test of two theories. International Political Science Review 32: 283-302.

Mellon J (2013) Internet search data and issue salience: The properties of Google Trends as a measure of issue salience. Journal of Elections, Public Opinion \& Parties 1-28.

Mishler W and Rose R (2001) What are the origins of political trust? Testing institutional and cultural theories in post-communist societies. Comparative Political Studies 34: 30-62.

Morris SD and Klesner JL (2010) Corruption and trust: Theoretical considerations and evidence from Mexico. Comparative Political Studies 43: 1258-1285.

Pharr SJ (2000) Officials' Misconduct and Public Distrust: Japan and the Trilateral Democracies. In: Pharr SJ and Putnam RD (eds) Disaffected Democracies: What's Troubling the Trilateral countries? Princeton: Princeton University Press, pp. 173-202.

Pollock W, Barabas J, Jerit J, et al. (2015) Studying media events in the European Social Surveys across research designs, countries, time, issues, and outcomes. European Political Science 14: 394-421.

Riera P, Barberá P, Gómez R, et al. (2013) The electoral consequences of corruption scandals in Spain. Crime, Law and Social Change 60: 515-534.

Rottinghaus B (2014) Political scandal in American politics. PS: Political Science \& Politics 47: 348-350.

Solaz H, De Vries CE and De Geus R (2017) In-group loyalty and the electoral punishment of corruption. Unpublished manuscript.

Villoria M, Van Ryzin GG and Lavena CF (2013) Social and political consequences of administrative corruption: A study of public perceptions in Spain. Public Administration Review 73: 85-94.

Zaller J (1992) The Nature and Origins of Mass Opinion. Cambridge, England: Cambridge University Press. 